\title{
Review of "The Table Comes First: family, France, and the Meaning of Food" by Adam Gopnik
}

\author{
Mark C Pachucki
}

Keywords: Aesthetics, Historical development, Social conditions of taste preferences

Scholars of flavor and food preferences have shown us that a surprisingly difficult question to answer is, "why do you eat what you eat?" In The Table Comes First: Family, France, and the Meaning of Food [1], Adam Gopnik attempts to address this and a similarly vexing question, "why do we care so much about our food?" by tracing the roots of what happens at the dinner table. Written with both everyday eaters and scholars of food in mind, Gopnik interweaves ideas about the development and meanings of taste with the historical and social circumstances around which we make choices about food and evaluate flavors. His compelling narrative strikes an engaging balance between the scholarly and the experiential.

One of his most well crafted sections concerns the origins and manifestations of our tastes in food. In surveying theories of taste from philosophers to economists, Gopnik argues that disputes about taste are centered around several kinds: "small taste" (the flavor of what we put in our mouths), "big taste" (how we make aesthetic choices in our lives), "mouth taste" (salty, sweet, buttery, bitter), and "moral taste" (how decisions resonate with the ethos of an era). Exploring the origins of restaurants and recipes, he observes France as an oversize influence in shaping the eaters we have become today, which echoes how the eater and cook that he has become affects his family's relationship with food. Conversations with restaurateurs add perspective to questions around how flavors are deconstructed in contemporary cooking, of challenges in trying to eat locally, and how carnivorism and vegetarianism are shaped by innate taste and ethics. Interspersed throughout are short correspondences with a long-dead historical figure with whom Gopnik feels a strong culinary affinity. Though these interludes could seem a literary gimmick, his lucid writing largely compensates.

While the role physiology plays in taste is minimized, it is also not the book's topic. For Gopnik, "There may be nature-based explanations for why some ways [of eating] are taken more frequently than others, but they fail at the moment of specific choice, and the specific choice is all that counts" (p.109). Elsewhere, "...eating... is a social act before it is a purely sensory one; it calls on our moral taste more than our measuring tongue" (p.225). This book is a welcome spur towards more research on how choice and circumstance interacts with, confronts, and sometimes contradicts both innate and learned tastes.

\section{Competing interests}

The author declares that he has no competing interests.

Authors' contributions

MCP drafted this review.

\section{Authors' information}

Mark C Pachucki, PhD, is a sociologist whose research focuses on how networks of social relations shape our taste preferences and our health.

\section{Acknowledgements}

The author gratefully acknowledges the support of the Robert Wood Johnson Foundation for fellowship support.

Received: 4 July 2012 Accepted: 17 July 2012

Published: 1 October 2012

\section{Reference}

1. Gopnik A: The Table Comes First: Family, France, and the Meaning of Food. New York: Knopf; 2011:320. ISBN 978-0307593450.

\section{doi:10.1186/2044-7248-1-18}

Cite this article as: Pachucki: Review of "The Table Comes First: family, France, and the Meaning of Food" by Adam Gopnik. Flavour 2012 1:18.

\footnotetext{
Correspondence: pachuckim@chc.ucsf.edu

Robert Wood Johnson Foundation Health \& Society Scholars Program,

University of California San Francisco, 3333 California St, Suite 465, Campus

Box 0844, San Francisco, CA 94143-0844, USA
}

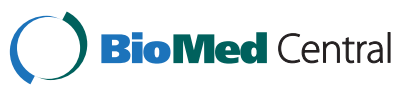

(C) 2012 Pachucki; licensee BioMed Central Ltd. This is an Open Access article distributed under the terms of the Creative Commons Attribution License (http://creativecommons.org/licenses/by/2.0), which permits unrestricted use, distribution, and reproduction in any medium, provided the original work is properly cited. 